\title{
Nutritional risk factors for gastric cancer in north-west Iran
}

\author{
Mohammadreza Pakseresht ${ }^{1}$, Janet Cade ${ }^{1}$, David Forman ${ }^{1}$, Reza Malekzadeh ${ }^{2}$ and Abbas Yazdanbod ${ }^{3}$ \\ ${ }^{1}$ University of Leeds, Leeds, UK, ${ }^{2}$ Digestive Diseases Research Centre (DDRC), Tehran, Islamic Republic of Iran and \\ ${ }^{3}$ Ardabil University of Medical Sciences, Ardabil, Islamic Republic of Iran
}

North-west Iran has been recognized as a high-risk area for gastric cancer (GC), with Ardabil Province having some of the highest rates. GC is one of two main cancers, the risk for which may be modified by food and nutrition. However, few studies ${ }^{(1)}$ have described nutritional status in this area and no published studies have explored the link between diet and GC in Ardabil.

A population based case-control study was developed covering nine cities in Ardabil Province between August 2005 and August 2007 to investigate relationships between food groups, macro- and micronutrients and other local dietary habits and risk of GC.

A total of 293 cases (74\% male, 26\% female) and 304 controls (71\% male, 29\% female) aged 35-80 years were recruited. On average, cases were 3 years older than controls (66 (SD 11) years $v .63$ (SD 11) years) with a high level of illiteracy ( $80 \%$ of cases and $68 \%$ of controls; $P=0.001$ ). Of the men (both cases and controls) $50 \%$ reported being current or ex-smokers compared with $14 \%$ of female cases v. $4.5 \%$ of female controls. Controls consumed $50 \%$ more fruit and vegetables than cases $(P<0.0001)$. Analysis of the FFQ showed that controls consumed significantly more carbohydrate, protein, fibre, $\mathrm{Zn}, \mathrm{Fe}, \mathrm{Ca}$ and vitamin $\mathrm{C}$ than cases. However, cases consumed significantly more PUFA than controls. Controls were more likely than cases to own a refrigerator $(99 \%$ v. 96\%; $P=0.02)$ and to have used it for longer (19 years $v .17$ years; $P=0.007$ ). Consumption of highly-salted and/or high-temperature-roasted seeds (as a local dietary habit) was more common in cases than controls. Of cases $70 \% v .50 \%$ of controls reported frying as their favourite method of cooking $(P<0.0001)$. Regression models were created to assess the impact of foods and nutrients on the risk of GC adjusting for age, gender, education, income, smoking, past history of stomach disease and duration of using refrigerator (Table). The results showed a significant positive association with intake of highly-salted seeds, nuts, total fat intake and frying and risk of GC. In contrast, consumption of fruits and vegetables and vitamin $\mathrm{C}$ had a protective effect in all models.

\begin{tabular}{|c|c|c|c|c|c|c|c|c|}
\hline Foods & OR & $95 \% \mathrm{CI}$ & Nutrients & OR & $95 \% \mathrm{CI}$ & Cooking & OR & $95 \% \mathrm{CI}$ \\
\hline Fruits and veg (every $50 \mathrm{~g}$ ) & 0.84 & $0.80,0.88$ & Fat (every $20 \mathrm{~g}$ ) & 1.38 & $1.21,1.60$ & Seeds (salted and roasted $v$. no cooking) & 2.45 & $1.31,4.58$ \\
\hline Raw leafy veg (every $10 \mathrm{~g}$ ) & 0.87 & $0.80,0.95$ & Vitamin C (every $10 \mathrm{mg}$ ) & 0.81 & $0.76,0.86$ & Frying (yes $v$. no) & 2.18 & $1.43,3.32$ \\
\hline Onions (every $10 \mathrm{~g}$ ) & 0.38 & $0.18,0.81$ & Fe (every $5 \mathrm{mg}$ ) & 0.40 & $0.27,0.59$ & & & \\
\hline Tomatoes (every $10 \mathrm{~g}$ ) & 0.63 & $0.53,0.76$ & $\mathrm{Zn}$ (every $5 \mathrm{mg}$ ) & 0.42 & $0.28,0.64$ & & & \\
\hline Nuts (every $10 \mathrm{~g}$ ) & 1.47 & $1.12,1.93$ & & & & & & \\
\hline
\end{tabular}

Nuts (every $10 \mathrm{~g}$ )

veg, vegetables.

The study demonstrated a negative relationship between consumption of fruits and vegetables and vitamin C, which has an important role in antioxidant activities and cell membrane and genome integrity. A recent systematic literature review on nutrition and GC supports these findings ${ }^{(2)}$. A high incidence rate of GC in Ardabil despite accessibility of healthy foods implies low general knowledge of appropriate food choice and preparation.

1. Dastgiri S, Mahdavi R, Tutunchi H \& Faramarzi E (2006) Public Health Nutr 9, 996-1000.

2. World Cancer Research Fund/American Institute for Cancer Research (2007) Food, Nutrition, Physical Activity and the Prevention of Cancer: A Global Perspective. Washington, DC: AICR. 